\title{
Health care needs and use of health care services among newly arrived Syrian refugees: a cross-sectional study
}

\author{
Anna Oda RN MN, Andrew Tuck MA, Branka Agic PhD, Michaela Hynie PhD, Brenda Roche PhD, \\ Kwame McKenzie MD
}

\section{Abstract}

Background: Canada welcomed 33723 Syrian refugees between November 2015 and November 2016. This paper reports the results of a rapid assessment of health care needs and use of health care services among newly arrived Syrian refugees in Toronto.

Methods: A cross-sectional study was conducted in Toronto among Syrian refugees aged 18 years or more who had been in Canada for 12 months or less. Participants were recruited initially through distribution of flyers in hotels and through direct referrals and communication with community and settlement agency partners, and then through snowball sampling. We collected sociodemographic information and data on self-perceived physical health and mental health, unmet health care needs and use of health care services.

Results: A total of 400 Syrian refugees (221 women [55.2\%] and 179 men [44.8\%]) were enrolled. Of the 400,209 (52.2\%) were privately sponsored refugees, 177 (44.2\%) were government-assisted refugees, and $12(3.0 \%)$ were refugees under the Blended Visa Office-Referred Program. They reported high levels of self-perceived physical and mental health. Over $90 \%$ of the sample saw a doctor in their first year in Canada, and $79.8 \%$ had a family doctor they saw regularly. However, almost half $(49.0 \%)$ of the respondents reported unmet health care needs, with the 3 most common reasons reported being long wait times, costs associated with services and lack of time to seek health care services.

Interpretation: Many factors may explain our respondents' high levels of self-perceived physical and mental health during the first year of resettlement, including initial resettlement support and eligibility for health care under the Interim Federal Health Program. However, newly arrived Syrian refugees report unmet health care needs, which necessitates more comprehensive care and management beyond the initial resettlement support.

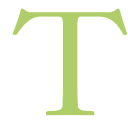
he Syrian refugee migration is one of the largest humanitarian crises in recent history. It is estimated that almost 4.9 of the 21 million refugees worldwide are from Syria. ${ }^{1}$ Between November 2015 and November 2016, Canada welcomed 33723 Syrian refugees, including 17627 government-assisted refugees, 12651 privately sponsored refugees and 3445 refugees under the Blended Visa Office-Referred Program. ${ }^{2}$ About $43 \%$ of all arrivals to Canada have landed in Ontario, with almost $40 \%$ of these coming to Toronto. ${ }^{2}$ Before and during the migration journey, many refugees experience hardships and stressful life events, including conflict-related violence, loss of family members, exploitation, injuries and poor nutrition, that put them at risk for physical and mental health problems. ${ }^{3,4}$ Research suggests that refugees have unique health care needs that are different from those of the general Canadian population; they also experience barriers to accessing services. ${ }^{5}$ Before arriving in Canada, Syrian refugees have a medical history taken and a physical examination conducted, but the results are not shared with local service providers. ${ }^{6}$ The absence of this data makes the development of needsbased health care planning and the development of appropriate services problematic. ${ }^{7}$

The current study was funded by health care planners in Toronto to help them develop an appropriate service response to the influx of Syrian refugees. The specific aims of the study were to examine the health care needs of Syrian refugees in Toronto within their first few months of arrival; document

Competing interests: None declared.

This article has been peer reviewed.

Correspondence to: Anna Oda, anna.oda@camh.ca

CMAJ Open 2017. DOI:10.9778/cmajo.20160170 
self-reported use of health care services among newly arrived Syrian refugees; and investigate perceived health of this population.

\section{Methods}

\section{Study design}

We used a cross-sectional interview design to provide a snapshot of the health, health care needs and use of health care services among Syrian refugees in their first year in Canada.

\section{Setting}

The study took place in Toronto. Interviews were conducted in hotels where Syrian refugees were initially hosted, in participants' homes and at partnering community and settlement agencies including COSTI Immigrant Services (a settlement agency in Toronto), the Arab Community Centre of Toronto, the Canadian Centre for Victims of Torture and Armenian Family Support Services.

\section{Participants}

Recruitment and data collection occurred between April and September 2016. The aim was to sample newly resettled Syrian refugees across the Greater Toronto Area. When our team proposed the study, in January 2016, it was expected that nearly 4000 new adult Syrian refugees would have arrived in Toronto. We estimated that a sample size of 400 would have good statistical power (based on a population size of 4000, with $95 \%$ confidence level and 5\% margin of error) and therefore proposed to collect information from about $10 \%$ of these refugees over the 6 months of the study. Inclusion criteria were: Syrian refugee who speaks Arabic or English, has been in Canada for 12 months or less, and is 18 years of age or more.

Initially, participants were recruited through the distribution of research flyers in hotels and through direct referrals and communication with community and settlement agency partners. Subsequently, news of the study spread by word of mouth.

\section{Data collection}

Participants could choose to complete the survey in Arabic or English themselves or have a face-to-face quantitative interview with the research assistant, who was fluent in Arabic and English. The interview took about half an hour.

We collected data using 3 survey tools: the Toronto Central Local Health Integration Network (TC LHIN) sociodemographic questionnaire, ${ }^{8}$ the RAND 36-Item Health Survey $\left(\right.$ RAND-36) ${ }^{9}$ and the Canadian Community Health Survey questions on use of health care services and unmet health care needs. ${ }^{10}$ We selected these 3 measures because they best addressed this study's research aims; moreover, the TC LHIN sociodemographic questionnaire and the RAND-36 have been translated and validated with Arabic-speaking populations (see Appendix 1, available at www.cmajopen.ca/ content/5/2/E354/suppl/DC1). ${ }^{8,9}$

Using the Arabic version of the TC LHIN sociodemographic questionnaire, the research assistant asked participants questions about their sponsor (government or private sponsor), date of arrival in Canada, sex, language preference when speaking with health care providers, education, and chronic illnesses or disabilities. The Arabic version of the RAND-36 was also used. The RAND-36 consists of 36 items that measure 8 health scales: physical functioning, bodily pain, role limitations due to physical health problems, general health perceptions, role limitations due to personal or emotional problems, general mental health, social functioning and energy/fatigue in the previous 4 weeks. ${ }^{9}, 11$ The questions from the Canadian Community Health Survey relating to use of health care services and unmet health care needs were verbally translated by the research assistant.

\section{Statistical analysis}

We computed descriptive statistics for sociodemographic variables and unmet health care needs and use of health services. To calculate RAND-36 scores, we followed the original RAND-36 scoring recommendations. ${ }^{11}$ First, we calculated the raw scores for the 8 health scales. Raw scores range from $0-100$, with higher scores indicating a more favourable health state. ${ }^{11}$ After calculating the raw score for each of the 8 scales, we weighted the scores based on the item response theory method to produce T-scores, and normalized them against a standardized American population. ${ }^{12}$ We then summed the T-scores together to form 2 composite scores, for physical health and mental health. ${ }^{12}$ The RAND-36 is standardized against the American population, and comparisons between our sample and US RAND-36 scores are presented. We did not have available data on the Canadian population.

\section{Ethics approval}

Research ethics approval was obtained from the Centre for Addiction and Mental Health and York University.

\section{Results}

\section{Sample characteristics}

A total of 500 Syrian refugees who met the study inclusion criteria were approached for the study, of whom 463 were interested in taking part. We randomly selected 400 people to reach our target sample. Most of our sample preferred that the survey questions be read to them in Arabic in a faceto-face interview rather than completing the survey questions themselves.

Of the 400 participants, 221 (55.2\%) were women and $179(44.8 \%)$ were men (Table 1). Participants ranged in age from 18 to 86 years, with the largest number being of working age. A total of 209 participants $(52.2 \%)$ were privately sponsored refugees, 177 (44.2\%) were government-assisted refugees, and $12(3.0 \%)$ were refugees under the Blended Visa Office-Referred Program; in 2 cases $(0.5 \%)$ refugee status was unknown. Of the 209 privately sponsored refugees, 191 (91.4\%) were sponsored by the Armenian community and $12(5.7 \%)$ by a Catholic church. On average, privately sponsored refugees were 10 years older than governmentassisted refugees. 


\section{OPEN}

Research

The participants had been in Canada for less than 1 month to 1 year; the average length of residence was 4.4 (standard deviation 2.24) months. On average, privately sponsored refugees had resided in Canada longer than government-assisted refugees. Whereas $69(39.0 \%)$ of all government-assisted refugees were interviewed in hotels where they were initially hosted, all privately sponsored refugees were interviewed in the community where they were resettled.

Low education levels were noted in the sample, with more than half of participants (217 [54.2\%]) reporting a high school education or less. A total of 238 participants (59.5\%) reported that they would prefer to speak to health care providers in Arabic.

\section{Perceived physical and mental health}

Of the 400 participants, 203 (50.8\%) reported that their current health was similar to that of a year earlier, 131 (32.8\%) reported having better health, and $66(16.5 \%)$ reported having worse health (Table 2). Our sample had higher than normal perceived physical and mental health when standardized to the US population that the RAND-36 is based on.

A total of 105 participants (26.2\%) reported having 1 or more of the following conditions: chronic illness, developmental disability, learning disability, mental illness or physical disability. Among those with a chronic illness, 56 people

\begin{tabular}{|c|c|}
\hline Characteristic & $\begin{array}{l}\text { No. }(\%) \text { of } \\
\text { participants* } \\
n=400\end{array}$ \\
\hline Age, mean $\pm S D$, yr & $40.59 \pm 14.91$ \\
\hline Female sex & $221(55.2)$ \\
\hline \multicolumn{2}{|l|}{ Sponsorship status } \\
\hline Privately sponsored & 209 (52.2) \\
\hline Government-assisted & $177(44.2)$ \\
\hline Blended Visa Office-Referred Program & $12(3.0)$ \\
\hline Prefer not to answer & $2(0.5)$ \\
\hline Residency in Canada, mean $\pm \mathrm{SD}$, mo & $4.43 \pm 2.24$ \\
\hline \multicolumn{2}{|l|}{ Education† } \\
\hline Secondary or less & $217(54.2)$ \\
\hline High school & $84(21.0)$ \\
\hline Bachelor's degree or higher & $99(24.7)$ \\
\hline \multicolumn{2}{|l|}{ Preferred language } \\
\hline Arabic & $238(59.5)$ \\
\hline Armenian & $116(29.0)$ \\
\hline English & $35(8.8)$ \\
\hline Otherł & $11(2.8)$ \\
\hline \multicolumn{2}{|c|}{$\begin{array}{l}\text { Note: SD = standard deviation. } \\
\text { *Except where noted otherwise. } \\
\text { †In Syria, secondary is grades } 7-9 \text { and high school is grades 10-12. } \\
\text { fIncludes Turkish and Kurdish. }\end{array}$} \\
\hline
\end{tabular}

reported cardiovascular diseases, 29 people reported diabetes, and 20 people reported musculoskeletal diseases.

\section{Health care needs and use of health care services}

Nearly all participants (365 [91.2\%]) reported seeing a doctor at least once since arriving in Canada (Table 3). More than three-quarters $(79.8 \%)$ reported having a family doctor, whom they had seen, on average, every other month since arrival.

Despite seeing health care providers on arrival in Canada, almost half of the participants (196 [49.0\%]) reported an

\section{Table 2: Raw scores on the RAND 36-Item Health Survey}

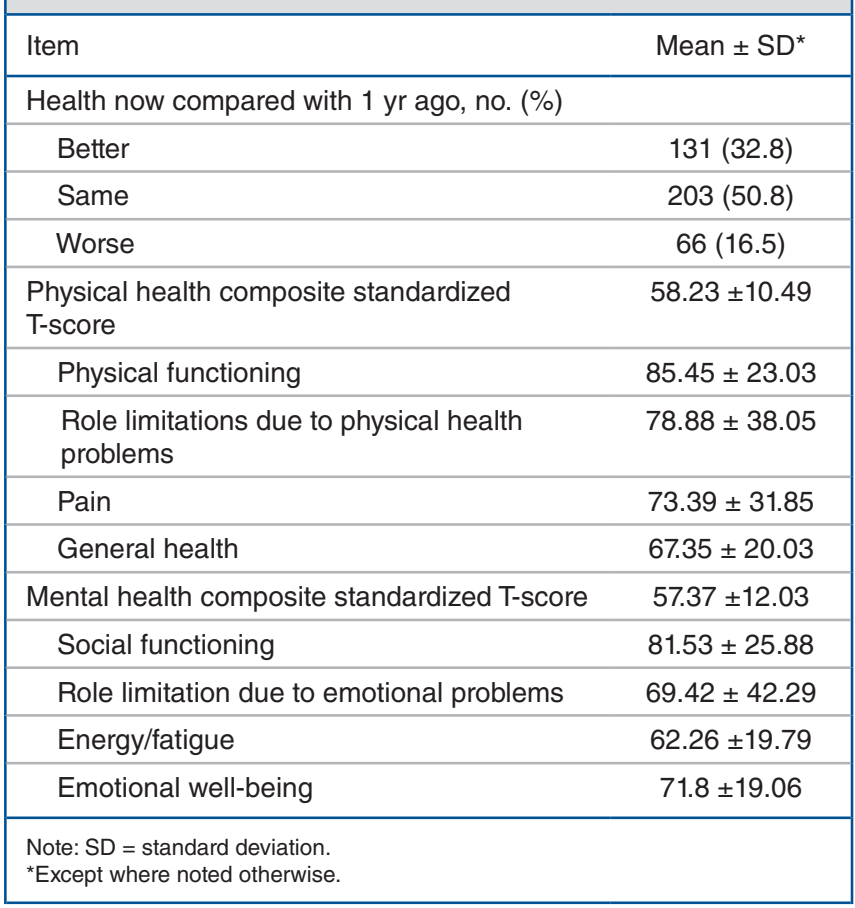

Table 3: Frequency of unmet health care needs and use of health care services

\begin{tabular}{|c|c|}
\hline Variable & $\begin{array}{l}\text { No. }(\%) \text { of } \\
\text { participants }\end{array}$ \\
\hline Has unmet health care needs & $196(49.0)$ \\
\hline Has family doctor & $319(79.8)$ \\
\hline \multicolumn{2}{|l|}{$\begin{array}{l}\text { Has talked to health care provider about } \\
\text { physical and/or mental health }\end{array}$} \\
\hline Doctor & $365(91.2)$ \\
\hline Eye specialist & $194(48.5)$ \\
\hline Dentist & $168(42.0)$ \\
\hline Social worker & $58(14.5)$ \\
\hline Other specialist* & $35(8.8)$ \\
\hline Other allied health care provider $†$ & $52(13.0)$ \\
\hline
\end{tabular}


unmet health care need. Most (165 [84.2\%]) of the 196 respondents who reported an unmet health care need mentioned only 1 type, including treatment of a physical health problem or dental care. The 3 most common reasons reported for respondents' not having had their health care needs met were long wait times, costs associated with services and lack of time to seek health care services.

\section{Interpretation}

This study offers a snapshot of sociodemographic characteristics, use of health care services, difficulties in accessing health care services and differences in these variables between privately versus government-assisted refugees among a sample of Syrian refugees newly resettled in Toronto. Newly resettled Syrian refugees are a heterogeneous group, with differences in age, preferred language and level of education.

A higher proportion of our sample of Syrian refugees than of the general Canadian population did not have access to a family doctor $(20.2 \%$ v. $14.9 \%){ }^{13}$ This relatively high proportion is likely related in part to the circumstances around time of arrival and to the fact that some of our participants were still residing in hotels at the time of the interview. Almost half (49.0\%) reported unmet health care needs, much higher than the rate of $11.2 \%$ among the general Canadian population. ${ }^{14}$ The reasons reported by our participants for unmet health care needs are similar to those reported in the national data, including long wait times, unavailability of services at the time required and costs. ${ }^{14}$ Furthermore, a lack of appropriate services leaves many refugees underserviced. ${ }^{15}$ The high proportion of refugees with unmet health care needs in our study and the reasons associated with unmet needs highlight the existing gaps in the Canadian health care system and indicate that more comprehensive care and management is required beyond the initial support provided on refugee resettlement.

Our findings are in line with a previous study on refugee health that showed that, during the first year after arrival in Canada, refugees report better health than the average Canadian population. ${ }^{16}$ Evidence suggests that the high perceived health status may be partially attributable to the initial resettlement support and access to health care services through the Resettlement Assistance Program or private sponsorship, which is offered for up to 1 year. ${ }^{17}$ Refugees are also eligible for the Interim Federal Health Program, also offered for up to 1 year, which helps cover the cost of certain medications and dental costs. ${ }^{17}$ Although our sample perceived their health as good, over one-quarter reported 1 or more chronic illnesses or disabilities. This is not surprising considering that diabetes and cardiovascular diseases are noted as the most prevalent health concerns among Syrian refugees who are screened through the immigration medical examination before coming to Canada. ${ }^{18}$ Our findings also coincide with reports indicating the high prevalence of noncommunicable diseases in the Syrian population. The literature suggests that noncommunicable diseases among Syrian refugees in Jordan posed the highest burden on the Jordanian health care sys- tem. ${ }^{19,20}$ It has been reported that refugees are at risk for deteriorating mental and physical health soon after arriving in Canada. ${ }^{17,21,22}$ Our findings on unmet health care needs suggest a course toward this outcome. In addition to the preexisting health problems before migration, such as injuries and chronic illnesses, after they resettle in Canada, refugees are more likely than the general population to experience socioeconomic barriers, which may also contribute to deterioration of their health status. ${ }^{17}$

Our findings reflect the realities of newly arrived Syrian refugees in the Toronto census metropolitan area, where a higher proportion of privately sponsored refugees (56.3\%) than government-assisted refugees (34.2\%) have resettled. ${ }^{23}$ The level of education reported by our participants is similar to that reported by Immigration, Refugees and Citizenship Canada: almost $81 \%$ of Syrian refugees in Ontario had 12 years or less of formal education, ${ }^{23}$ compared with $75.3 \%$ of our respondents. Although for the purpose of our research we asked only about the language participants would feel most comfortable speaking with health care providers and not about their mother tongue, our finding that $40.5 \%$ would prefer a language other than Arabic is consistent with data indicating that the mother tongue of over $10 \%$ of Syrian refugees in Ontario was not Arabic. ${ }^{23}$ This finding suggests that Syrian refugee minorities such as Armenians and Kurds resettled in Toronto may prefer to speak their mother tongue, which has potential implications for provision of health care services.

\section{Limitations}

Results from this study may have limited generalizability because a high proportion of government-assisted refugees were interviewed in hotels and had been in Canada for a short time. The data collected in this study were based on selfreport. The snowball method of sampling may have introduced bias, and the results may reflect social desirability bias. The restriction to refugees who could speak only Arabic or English may have limited participation. However, in the Toronto context, our approach and findings are useful in offering a lens through which the service needs of this new refugee group can be considered.

\section{Conclusion}

Canada's commitment to increase the number of refugees accepted necessitates further investment in short-term support to meet the health care needs of this population during the initial stages of resettlement. Further assessment of refugees' personal health information records would be useful for accurate reporting of use of health care services by newly arrived Syrian refugees. Moreover, longitudinal research is needed to explore Syrian refugees' health, use of health care services and health care needs as they change in subsequent years after resettlement in Canada. Addressing long wait times and investing in covering further medical costs such as dental care under the Interim Federal Health Program could reduce long-term public costs and ensure that newly arrived refugees are reaching their potential in their new home. 


\section{References}

1. Figures at a glance. Geneva: United Nations High Commissioners for refugees; 2016. Available: www.unhcr.org/figures-at-a-glance.html (accessed 2016 Oct. 16).

2. \#WelcomeRefugees: key figures. Ottawa: Citizenship and Immigration Canada; 2016. Available: www.cic.gc.ca/english/refugees/welcome/milestones.asp (accessed 2016 Nov. 4)

3. Hansson E, Tuck A, Lurie S, et al. Improving mental health services for immigrant, refugee, ethno-cultural and racialized groups: issues and options for service improvement. Ottawa: Mental Health Commission of Canada; 2010. Available: www.mentalhealthcommission.ca/SiteCollectionDocuments/ Key_Documents/en/2010/Issues_Options_FINAL_English\%2012Nov09.pdf (accessed 2016 Oct. 12).

4. Pottie K, Greenaway C, Feightner J, et al. Evidence-based clinical guidelines for immigrants and refugees. CMA7 2011;183:E824-925.

5. Beiser M. Resettling refugees and safeguarding their mental health: lessons learned from the Canadian refugee resettlement project. Transcult Psychiatry 2009;46:539-83

6. Pottie K, Hui C, Kirmayer L, et al. Caring for a newly arrived Syrian refugee family. CMA7 2016;188:207-11.

7. Patients first: a proposal to strengthen patient-centred health care in Ontario. Toronto: Ministry of Health and Long-Term Care; 2015. Available: www. health.gov.on.ca/en/news/bulletin/2015/docs/discussion_paper_20151217.pdf (accessed 2016 Oct. 12).

8. Wray R, Agic B, Bennett-AbuAyyash C, et al. We ask because we care: the TriHospital and Toronto Public Health (TPH) Health Equity Data Collection Research Project Report. Toronto: Centre for Addiction and Mental Health; 2013. Available: www.porticonetwork.ca/web/health-equity/initiatives/tri-tph (accessed 2016 Oct. 12)

9. Coons SJ, Alabdulmohsin SA, Draugalis JR, et al. Reliability of an Arabic version of the RAND-36 Health Survey and its equivalence to the US-English version. Med Care 1998;36:428-32.

10. Canadian Community Health Survey (CCHS): annual component - 2010 questionnaire. Ottawa: Statistics Canada; 2010. Available: www23.statcan.gc.ca/imdb -bmdi/pub/instrument/3226_Q1_V7-eng.pdf (accessed 2016 Feb. 14).

11. Hays RD, Sherbourne CD, Mazel RM. The RAND 36-Item Health Survey 1.0. Health Econ 1993;2:217-27.

12. Hays RD, Prince-Embury S, Chen H. RAND-36 Health Status Inventory. San Antonio (TX): Psychological Corporation; 1998.

13. Health Fact Sheets 2015: access to a regular medical doctor, 2014. Ottawa: Statistics Canada; 2015. Cat no 82-625-X. Available: www.statcan.gc.ca/pub/82 -625-x/2015001/article/14177-eng.htm (accessed 2017 Feb. 8).

14. Health Fact Sheets 2015: unmet health care needs, 2014. Ottawa: Statistics Canada; 2016. Cat no. 82-625-X. Available: www.statcan.gc.ca/pub/82-625-x/ 2016001/article/14310-eng.htm (accessed 2017 Feb. 8).

15. McKeary M, Newbold B. Barriers to care: the challenges for Canadian refugees and their health care providers. F Refug Stud 2010;23:523-45.

16. Beiser $M$. The health of immigrants and refugees in Canada. Can 7 Public Health 2005;96:S30-44.

17. Health status and social capital of recent immigrants in Canada: evidence from the Longitudinal Survey of Immigrants to Canada. Ottawa: Citizenship and
Immigration Canada; 2005. Available: www.cic.gc.ca/english/resources/ research/immigrant-survey/section5.asp (accessed 2016 Nov. 14).

18. Population profile: Syrian refugees. Ottawa: Citizenship and Immigration Canada; 2015. Available: http://lifelinesyria.ca/wp-content/uploads/2015/11/EN -Syrian-Population-Profile.pdf (accessed 2016 Nov. 15)

19. Noncommunicable diseases (NCD) country profiles, 2014: Syrian Arab Republic. Geneva: World Health Organization; 2014. Available: www.who.int/ nmh/countries/syr_en.pdf (accessed 2016 Nov. 14).

20. Doocy S, Lyles E, Akhu-Zaheya L, et al. Health service utilization among Syrian refugees with chronic health conditions in Jordan. PLoS One 2016;11:e0150088.

21. $\mathrm{Ng} \mathrm{E}$, Pottie K, Spitzer D. Limited official language proficiency and decline in health status: a dynamic view from the Longitudinal Survey of Immigrants in Canada. Health Rep 2011;22:1-10.

22. Gushulak BD, Pottie K, Hatcher Roberts J, et al. Migration and health in Canada: health in the global village. CMA7 2011;183:E952-8.

23. Syrian refugee resettlement. Ottawa: Government of Canada; 2016. Available: http://open.canada.ca/data/en/dataset/ca243c40-a6d3-4a46-a578-4fad4369df0? _ga $=1.214614100 .2121115801 .1479500980$ (accessed 2017 Feb. 22).

Affiliations: Health Equity (Oda, Tuck, Agic, McKenzie), Centre for Addiction and Mental Health; Dalla Lana School of Public Health (Agic) and Department of Psychiatry (McKenzie), University of Toronto; Department of Psychology (Hynie), York University; Wellesley Institute (Roche, McKenzie), Toronto, Ont.

Contributors: Anna Oda conducted the literature review and wrote the manuscript. Andrew Tuck performed analyses. Andrew Tuck, Branka Agic, Michaela Hynie, Brenda Roche and Kwame McKenzie reviewed the manuscript for important intellectual content. All of the authors contributed to conceptualizing, designing and planning the study, and to analyzing and interpreting the results, approved the final version to be published and agreed to act as guarantors of the work.

Funding: This study was funded by the Toronto Central Local Health Integration Network.

Acknowledgements: The authors acknowledge the support, insight and expertise that Vince Pietropaolo provided to the research team. They also thank their collaborators who provided assistance in recruitment and support throughout the course of this study: the Arab Community Centre of Toronto, COSTI Immigrant Services, the Canadian Centre for Victims of Torture, Armenian Family Support Services, the Crossroads Clinic Women's College Hospital and St. Michael's Hospital. Finally, the authors are grateful to the study participants, without whom this research could not have been completed.

Supplemental information: For reviewer comments and the original submission of this manuscript, please see www.cmajopen.ca/content/5/2/ E354/suppl/DC1 